\title{
Workplace Incivility: The Slow Death of Organizational Efficiency
}

\author{
${ }^{1}$ Prof. Shravan Chandak, ${ }^{2}$ Dr. Ruchi Sao, ${ }^{3}$ Prof. Pritam Bhadade \\ ${ }^{1,2,3}$ Assistant Professor, Shri Ramdeobaba College of Engineering and Management, Nagpur \\ Email: chandaksj3@rknec.edu,saorn@rknec.edu,bhadadepr1@rknec.edu
}

\author{
Received: $20^{\text {th }}$ September 2018, Accepted: $11^{\text {th }}$ October 2018, Published: $31^{\text {st }}$ October 2018
}

\begin{abstract}
This study is an effort to identify various factors which contribute to workplace incivility and the identification of after effects of incivility at workplace through extensive literature review.

Workplace incivility represents aberrant behaviors demonstrated either by superiors, co-workers and customers. These behaviors are of low intensity in comparison to workplace bullying and has ambiguous nature; i.e., there might be no specific intention to cause harm to the person. The band of incivility ranges from having negative behaviour which may also lead to verbal aggression and physical aggression in some cases. There are basically two occurrence of incivility namely overt instances and covert instances. The former includes instances which can be seen such as aggressive behaviour whereas the latter represent the instances which are hidden and may not be visible but may have a long lasting impact on the employees.

The factors contributing to workplace incivility identified are organizational aspects, demographic variables, source of incivility, past experience to incivility, sociocultural perspectives and personality types.

The outcomes of incivility can be on organizational wellbeing or individual wellbeing or both. Workplace incivility aggravates to employee dissatisfaction, turnover intention, low conscientiousness, high instances of ostracism, low employee morale, low affective commitment and many more which are detrimental to organizational efficiency. Various studies have shown that incivility has effects on mental and physical health of the target. Incivility may be experienced by an individual or individuals belonging to a particular strata characterized on the basis of age, colour, gender, race, designation, financial background, caste or religion and alike.
\end{abstract}

\section{Keywords}

Organizational Aspects, Past Experience to Incivility, Personality Types, Sociocultural Perspectives, Source of Incivility, Workplace Incivility

\section{Introduction}

Andersson and Pearson (1999) (p. 457) defined workplace incivility is defined as "low-intensity deviant behaviour with ambiguous intent to harm the target, in violation of workplace norms for mutual respect [1]." There are important components or characteristics that differentiate workplace incivility from other negative workplace behavioral constructs. It has low-intensity and actions are not perceived as overtly threatening by target; the intensions are difficult to discern; it involves violation of workplace norm for mutual respect and it can be instigated not only by supervisor but also by co-workers or customers [2]. However, incivility generally does not warrant legal attention unlike sabotage or harassment. Irrespective of type of work, it is almost certain that most of the employees in the today's environment face incivility at workplace and such incidences appear to be on the rise [3].

Workplace incivility can have far more damaging effects on an organization than most of the leaders and managers can anticipate. Various performance parameters have undesirable impact [4]. A lot of literature has been written defining and studying various dimensions of workplace incivility. Multiple scales have also been developed measure the impact of factors affecting workplace incivility as well as impact of that on organizations as well as individuals. There are various levels, forms and examples of incivility. Different individuals can perceive a behaviour as uncivil based on various actions and intensity of that action. For example, if person $\mathrm{X}$ responds to telephone call during an ongoing conversion with person $\mathrm{Y}$, person $\mathrm{Y}$ might treat this action as uncivil behaviour or he might perceive it as routine business requirement. However insulting a co-worker or influencing others to stop cooperating a specific individual will be treated as uncivil behaviour by almost all individuals. Incivility can be instigated in various forms like taking credit for someone else's work, not responding properly, not acknowledging work of an individual, packing up and leaving before an event is concluded, withholding information, racism, casual sexism, ageism etc. While authors are unable to find any exclusive research work or academic literature on levels of incivility, certain levels have been mentioned starting from verbal-passive and indirect incivility (e.g. Showing no interest in clarifying false information) to Physical-active \& direct (e.g. sending cold non-verbal messages) [5]. The acts of incivility can be also be broadly classified as overt (obvious) and covert (concealed) ones. 
Following are the various factors that affect workplace incivility and would be discussed in detail in result and discussion part.

- Organizational aspects

- Demographic variables

- Source of incivility

- Past experience to incivility

- Sociocultural perspectives

- Personality types

The impact of workplace incivility can be classified as under:

\section{- Organizational Wellbeing:}

Organizational scholars have noted that there are number of outcomes of incivility which are detrimental to healthy workplace environment and organizational effectiveness. Naman Sharma and V Singh in their study found that workplace incivility has negative impact on job satisfaction and also results in increased turnover intentions [6]. It has results in increased absenteeism [7] affecting productivity and other parameters because of absenteeism. The ultimate impact of workplace incivility is decreased quality of services being provided to customers [8].

\section{- Individual Wellbeing:}

Many studies have been done with respect to impact of incivility of individual well-bring of employees which shows that it has negative psychological impact such as feelings of stress [9] burnout [10] and even insomnia [11]. Brad Estes and Jia Wang have done a meta-analytical study on the impact of workplace incivility on individual as well as organizational performances. The major impact on individual performance observed are Cognitive and affective impartment of individual, Increased Psychological distress such as depression and anxiety, Lower self-esteem, Feeling of guilt and shame, Expression of anger and outrage in subtle acts of retaliation, Work slowdown and wastage of time in an attempt to avoid the instigator. Incivility has only negative impact of individuals those who directly experience incivility but also on those who witness it towards others [12].

\section{Materials and Methods}

The present study reports factors affecting workplace incivility and its impact on organizational wellbeing and individual wellbeing. On the basis of literature review, the factors contributing to workplace incivility are organizational aspects, demographic variables, Source of incivility, past experience to incivility, sociocultural perspectives and personality types. The aim of the study is to explore various dimensions of workplace incivility as a social process which includes sources of incivility; factors causing or factors acting as catalyst resulting in workplace incivility; impact of incivility of organizational as well as individual well-being.

Multiple studies have been done in isolation to each other studying impact of particular set of factors resulting in workplace incivility as well as impact of workplace incivility on selected set of organizational performance or individual well-being. This study is an attempt to study and organize large amount of work done previously about the workplace incivility and organize them to provide more meaningful insights for further research.

The study would give a conceptual model of workplace incivility.

\section{Results and Discussion}

This part discusses the factors affecting workplace incivility in detail.

\section{- Organizational Aspects:}

Eva Torkelson, Kristoffer Holm, Martin Bäckström \& Elinor Schad have studied various organizational aspects which affecting workplace incivility. The researchers conducted a study of over 500 employees in education sector in Sweden and concluded that there are several organizational factors which impact uncivil behaviour at workplace. The identified factors are organizational changes, perceived job insecurity, low social support from co-workers, low social support from supervisors, low control and more demanding jobs. They concluded that employees working in organizations those have recently undergone or undergoing change, low job security, demanding jobs and low social support from co-workers has direct relation to instigated incivility. Research also found out that experiencing incivility from co-workers is one 
of the distinctive predictor that the target will also perpetrate similar behaviour. However, incivility from supervisor does not result in similar behaviour [13] .

\section{- Demographic Variables:}

It has also been proven in many studies that incivility is selective as well. i.e. employees who perpetrate incivility may not do it uniformly towards all co-workers or subordinates with equal intensity. Employees are indiscriminate based on various factors like gender, race of the target, age and person of particular color. Cortina et al. in their research at city government municipality relating gender and age to incivility found out that women who are not of advanced age face more risk of being target of workplace incivility as compared to male their counterparts. In a similar study at law enforcement agency linking incivility with race and age found out that employees of minority race irrespective of their age face increased risk of facing workplace incivility. In line with the previous two research mentioned above, Cortina et al. conducted a study of about 20,000 personnel of US military. They found out that gender and race of the employee interact while predicting uncivil treatment. i.e. women of particular race have higher chances of facing incivility than any other gender-race group. The overall study found out that gender is major influencer as compared to race and women faced more cases of incivility irrespective of their race. [14]

\section{- Source of Incivility:}

Incivility can be instigated by various sources like supervisor, co-worker, subordinate and customers as well. Rima C. Tarraf in her research work with special reference to source of incivility found out that incivility from supervisor is more strongly related to job (dis)satisfaction and turnover intention while incivility from co-worker is more strongly associated with affective commitment. However, according to study if outcome of incivility are measured jointly (Supervisor and co-worker) the impact of incivility on organizational outcome is over estimated [15]. Michael Sliter et al found that co-worker incivility has considerable impact on absenteeism while customer incivility have considerable impact on two types of employee withdrawal namely tardiness and absenteeism [16].In the same study, researchers showed the interaction effect of customer and coworker incivility.

\section{- Past Experience of Incivility:}

Many researchers in their studies have found out employees who are being target of workplace incivility appear to be possible antecedent of perpetrating acts of incivility. Incivility from co-workers contributes to significant variance to instigation of incivility by victim [17]. Same results have been proven for both workplace bullying and aggression, that being a victim is of the strongest predictor of perpetration [18] [19].

\section{- Sociocultural Perspectives:}

Rajashi Ghosh in her meta-analytical study showed that socio-cultural norms can have huge impact on perceptions of incivility. For example, women in Asia might have higher probability of experiencing uncivil incidences as they are less likely to be accepted as leaders in patriarchal cultures in Asia. Similarly, reactions of witnesses may differ based on socio-cultural status of victim. Also behaviour or actions of instigators of incivility at workplace might be based upon target/victims' socio-cultural status [20].

\section{- Personality Types:}

Reactions of employees towards (perceived or experienced) workplace incivility can vary from individual to individual. Some employees might react differently than others towards similar incidences of incivility. The extent to which certain set of employees are affected than other differ and personality type can act one of the possible moderator towards reactions to incivility experienced at workplace. Courtney Lancaster (2014) in her research work with respect to personality factors of individual and incivility experienced at workplace found that 'agreeableness' act as moderator in relationship between experienced incivility and strain. Same study showed that individual those are high in neuroticism have more chances of experiencing strain, leading to inference that neuroticism effect the relationship of perceived incivility and psychological strain as one of the moderators. The findings also suggested that neuroticism acts as moderator with regards to influence of incivility from superior and turnover intention and turnover intentions are higher for individuals who are higher in neuroticism. [21] Sliter et al. has conducted a study in 2015 to study relation between personality type and perceived incivility. Researchers found that Trait anger, positive affect (PA) as well as negative affect (NA) are positively related to incivility perception while openness, agreeableness 
and emotional stability are related negatively. The study also found that maximum variation in incivility perception is explained by two personality traits i.e. trait anger and positive affect (PA) [22]. Sergey Mazuritsky also confirmed the results of Sliter et al. in his study and concluded that positive affect particularly is strong predictor of perception of incivility as compared to other parameters [23].

\section{Conclusion}

On the basis of literature review, it can be concluded that organizational aspects, demographic variables, source of incivility, past experience to incivility, sociocultural perspectives and personality types contribute towards workplace incivility. The outcomes of incivility can be on organizational wellbeing or individual wellbeing or both. Figure 1 is the proposed conceptual model encompassing various dimensions of incivility.

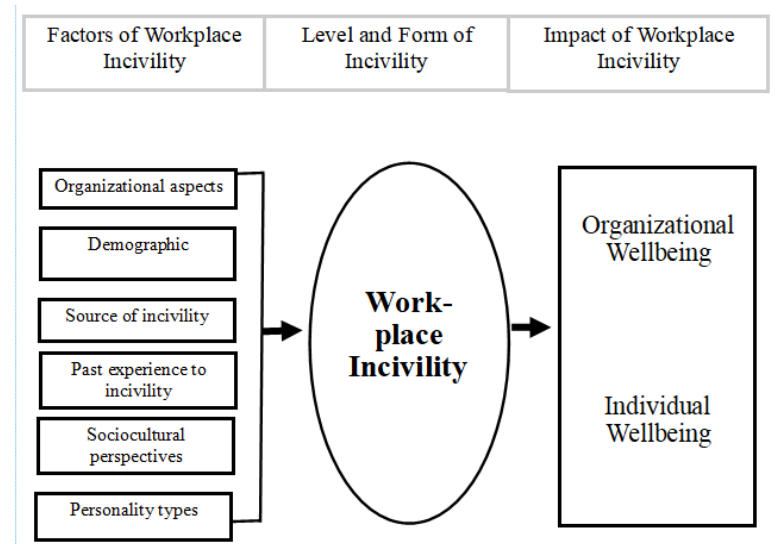

Figure 1: Workplace Incivility - Factors and Outcomes

The relation inter-alia between various factors contributing to workplace incivility can be studied in future. Also, the overall impact on organizational and individual wellbeing as proposed in the model can be studied and validated.

\section{References}

1. L. M. Andersson and C. M. Pearson, "Tit for tat? The spiraling effect of incivility in the workplace.", Academy of Management Review, p. 452-471, 1999.

2. P. Schilpzand, I. E. D. Pater and A. Erez, "Workplace incivility: A review of the literature and agenda for future research," Journal of Organizational Behavior, pp. 57-89, October 2016.

3. L. M. Cortina, V. J. Magley and R. D. Williams J. H \& Langhout, "Incivility in the workplace: Incidence and impact.," Journal of Occupational Health Psychology, 6(1), 64-80., 2001.

4. C. M. Pearson and L. M. A. \&. C. I. Porath, "Assessing and Attacking Workplace Incivility," Organizational Dynamics, vol. 29, no. 2, pp. 123-137, 2000.

5. "Types of Workplace Incivility," Available: https://www.tutorialspoint.com/workplace_civility/workplace_incivility_types.htm. [Accessed 2 September 2018].

6. N. S. \&. V. singh, "Effect of workplace incivility on job satisfaction and turnover intentions in India intentions in India," South Asian Journal of Global Business Research, vol. 5, no. 2, pp. 234-249, 2016.

7. M. Zia-Ud-Din and A. A. \&. M. A. Shabbir, "The Impact of Workplace Incivility on Employee Absenteeism and Organization Commitment," International Journal of Academic Research in Business and Social Sciences, vol. 7, no. 5, pp. 205-220, 2017.

8. C. Spiri, Meredith Brantley and J. McGuire, "Incivility in the workplace: A study of nursing staff in the Military Health System," Journal of Nursing Education and Practice, vol. 7, no. 3, pp. 41-46, 2017.

9. L. M. \&. S. P. E. Penney, " Job stress, incivility, and counterproductive work behavior (CWB): The moderating role of negative affectivity.," Journal of Organizational Behavior, vol. 26, no. 7, pp. 777-796, 2005. 
10. D. \&. M. Von Dierendonck, “ Aggressive behavior of passengers, conflict management behavior, and burnout among trolley car drivers," International Journal of Stress Management, p. 345-355, 2002.

11. C. A. Demsky, C. Fritz, L. B. Hammer and A. E. Black, "Workplace Incivility and Employee Sleep: The Role of Rumination and Recovery Experiences," Journal of Occupational Health Psychology, 2018.

12. K. K. K. \&. V. C. M. Montgomery, "Accounting for differences in norms of respect.," Group \& Organization Management, p. 248-268., 2004.

13. E. Torkelson, K. Holm, M. Bäckström and E. Schad, "Factors contributing to the perpetration of workplace incivility: the importance of organizational aspects and experiencing incivility from others," Work \& Stress, pp. 115-131, 2016.

14. L. M. Cortina, D. Kabat-Farr, E. A. Leskinen and M. H. a. V. J. Magley, "Selective Incivility as Modern Discrimination in Organizations: Evidence and Impact," Journal of Management, pp. 1-28, 2011.

15. R. C. Tarraf, "Taking a Closer Look at Workplace Incivility: Dimensionality and Source Effects," Electronic Thesis and Dissertation Repository. 642., 2012.

16. K. S. A. S. J. MICHAEL SLITER*, "The employee as a punching bag: The effect of multiple sources of incivility on employee withdrawal behavior and sales performance," Journal of Organizational Behavior, p. 121-139, 2012.

17. E. Torkelson, K. Holm, M. Bäckström and E. Schad, "Factors contributing to the perpetration of workplace incivility: the importance of organizational aspects and experiencing incivility from others," Work and Strees, vol. 30, no. 2, pp. 115-131, 2016.

18. G. T. A and L. H., "Interpersonal aggression in work groups: Social influence, reciprocal, and individual effects.," Academy of Management Journal, pp. 486-496, 2003.

19. S. A. E. S. Hauge L. J., "Individual and situational predictors of workplace bullying: Why do perpetrators engage in the bullying of others?," Work \& Stress., pp. 349-358, 2009.

20. R. Ghosh, "Workplace Incivility in Asia- How do we take a Socio-Cultural Perspective?," Human Resource Development International, vol. 20, no. 4, pp. 263-267, 2107.

21. C. Lancaster, "Personality Factors as Potential Moderators of Reactions to Experienced Workplace Incivility," April 2014.

22. M. Sliter and S. \&. J. S. M. Withrow, "It happened, or you thought it happened? Examining the perception of workplace incivility based on personality characteristics.," International Journal of Stress Management, vol. 22 , no. 1, pp. 24-45, 2015.

23. S. Mazuritsky, "Perceptions of Workplace Incivility Based on Personality Characteristics: A Replication," Guelph, Ontario, Canada, 2018. 